\title{
THE ASSESSMENT TOOL OF L2 LEARNERS' \\ PRAGMATIC COMPETENCE: \\ WRITTEN DISCOURSE COMPLETION TEST (WDCT)
}

\author{
Fauzul Aufa \\ University of Queensland
}

\begin{abstract}
Research studies have shown that pragmatic competence is teachable. The importance of teaching pragmatics has also been recognized, but still foreign language teachers are reluctant to teach pragmatics in their classrooms. This might be partly due to the lack of some valid methods for assessing pragmatic competence. This essay contends that while the Written Discourse Completion Test (WDCT) has some pitfalls, the WDCT effectively assesses learner's pragmatic competence.
\end{abstract}

Key words: pragmatic competence, teaching pragmatics, pragmatic competence assessments, Written Discourse Completion Test (WDCT)

\section{INTRODUCTION}

Pragmatic competence is the ability to communicate effectively that involves both grammatical and pragmatic knowledge (Thomas, 1983; Bachman, 1990). Bachman (1990) identifies pragmatic competence as consisting of two aspects: (1) illocutionary competence that enables us to use language to express a wide range of functions, and to interpret the illocutionary force of utterances or discourse, and (2) sociolinguistic competence that enables us to perform language functions in ways that are appropriate to that context. Considering the importance of appropriateness in language use in order to communicate successfully, English as a Foreign Language (EFL) learners require to learn and acquire pragmatic competence. Studies have showed that pragmatic competence can be taught explicitly in EFL classroom (Brock \& Nagasaka, 2005; Jernigan, 2007; Vitale, 2009; Taguchi, 2011; Sadhegi \& Foutooh, 2012). Still, due to the lack of valid tools 
in assessing learners' interlanguage pragmatic competence, teachers are uncertain to include it into their syllabus. Moreover, it is a difficult task to develop and design a communicative language testing to measure learners' pragmatic competence in EFL context. There are some tools used to assess L2 learners' pragmatic competence, such as role-plays, multiple-choice questionnaires, rating scale assessments, simulations, interview tasks, and Written Discourse Completion Test (WDCT).

Apparently, the popularity of WDCT has been widely recognized because of its practical use among other assessment tools. However, there has been an endless debate among language teachers whether the WDCT can be used to assess EFL learners' pragmatic competence. Thus, this essay argues that despite its limitation, the WDCT is an effective tool to assess the learners' pragmatic competence. It will then put forward five stages to construct the WDCT in assessing the learners' pragmatic competence.

\section{WDCT AND ITS BENEFITS}

Supporters of the WDCT assert that this test is able not only to test learners' pragmatic awareness, but also to assess learners' production on certain speech acts. In this test, the learners are asked to respond appropriately in written form based on short situational descriptions given (Jianda, 2006). For example, the teacher has the learners make a request to someone who is older and not close, and write it down in a natural way as they speak to a real person. At this point, the learners are expected to write a polite request since they make a request to an older person. Thus, they also have to pay attention to some variables, such as social distance, relative power, and degree of imposition in each situation before giving their response (Martinez-Flor, 2003; Decapua \& Dunham, 2007; Phisghadam \& Sharafadini, 2011). In line with this, Jie (2005) investigated how Chinese university EFL learners performed appropriately in making refusal and request acts in different pragmatic tests, namely Multiple-choice Discourse Completion Test (MDCT) and the WDCT. The results have generally shown that the WDCT demonstrated learners' actual pragmatic competence more than the MDCT did. More specifically, the learners were aware about the context, which are social distance and relative power that led them to produce appropriate speech acts. Therefore, the WDCT can be used to elicit learners' production in order to assess their pragmatic competence. 
Next, regarding the test's usefulness framework proposed by Bachman and Palmer (1996), reliability and validity aspects are considered essential in validation process. In relation to this, some researchers contend that the WDCT has been proved as a valid test so that the test can be used as an effective assessment of L2 leaners' pragmatic competence. According to Hudson, Detmer, and Brown, (1995), the WDCT adequately had high validity after applying some statistical procedures on six different test instruments, namely a self-assessment for the roleplay, a self-assessment for the DCT, a role-play, oral DCT, WDCT, and MDCT, for assessing pragmatic competence of English learners. Similarly, Yamashita (1996) quantitatively investigated the validity of six test instruments proposed by Hudson et al. (1995) to test Japanese as Second Language (JSL) learners' pragmatic competence. She indicated the same results as what Hudson et al. (1995) found. Following the research conducted by Hudson et al. (1996) and Yamashita (1996), Ahn (2005) also examined the same instruments by excluding the role-play and the oral DCT to examine pragmatic competence of Korean as Second Language (KSL) learners. The findings showed that the test instruments were also valid and applicable to KSL contexts. Hence, the WDCT, which is one of the test instruments of pragmatic competence, is reasonably valid even though it has been used to assess L2 learners' pragmatic competence of different target language teaching contexts.

Furthermore, the reliability of the WDCT has been affirmed as a measure of L2 learners' pragmatic competence. Jianda (2006) explored some methods to assess Chinese EFL learners' pragmatic competence. He evaluated three different test instruments, which are MDCT, WDCT, and Discourse Self-Assessment Test (DSAT). He quantitatively estimated the Cronbach alpha reliability of the WDCT which showed satisfactory result. Likewise, Roever (2005) also confirmed that the WDCT reasonably had high reliability in his research. Based on his analysis, this test was effective to assess L2 learners' pragmalinguistic knowledge of three speech acts, such as request, apology, and refusal. The results illustrated reasonable consistency in the test. In other words, it can be implied that the internal consistency reliability of the WDCT is highly satisfactory.

Focusing on the practicality of the test, the WDCT can be claimed as a highly effective tool to gather a large number of data quickly. For instance, if the teacher wants to assess L2 learners' pragmatic competence in big classes consisted of more than thirty students, the WDCT can be effectively administered. 
Particularly, the teacher does not need to take a long time to get as many responses as from the leaners (Roever, 2011). In addition, according to Kasper (2000), the teacher can control situational variables in the WDCT, such as social distance, familiarity, age, degree of imposition, and relative power between the speakers. What is more, this test does not need to be transcribed, so the teacher can easily analyse the result and know the level of learners' pragmatic competence.

\section{PITFALLS OF WDCT}

However, the WDCT also have some limitations. Firstly, the opponents of the WDCT use in language testing comment on its authenticity and compatibility with natural speech occurrences. Using a written form to elicit oral production cannot reflect the cognitive process involved in the interaction (Yamashita, 1996). More specifically, the realisation of targeted speech acts in the actual oral production is quite different from the written form. In addition, it is impossible to play conversational turns in the WDCT since it does not allow the assessment of speech act production in its real discourse context. It also lacks sequential orders in terms of the choice of strategy and the negotiation of meaning (Yamashita, 1996). It can be concluded that the WDCT does not demonstrate interactive aspect of oral performance in authentic conversation even though this test portrays the linguistic expression of speech acts.

Next, the WDCT does not seem to reflect the range of strategies use in speech acts employed by the learners. For instance, in oral performance, the learners use hesitations, repetitions, inversions, and longer supportive moves, which are missing in the WDCT. Rasekh and Alijanian (2012) claim that the WDCT is not preferable to be used to elicit learners' oral production in the speech acts. After comparing participants' responses collected from WDCT and role-plays regarding length and content of request acts used, they found that the learners used less alerters, supportive moves, head act strategies, internal modification used in the head acts in the WDCT compared to strategies used in the role-play. Hence, the learners cannot employ more variations in the WDCT since it has no interactive nature of real situations.

The further claim is that the nature of situations in the WDCT is considered as the simplification of the complexity of interactions in real oral communication. This is supported by Nurani (2009) who argues that the situations in the WDCT do 
not represent what the learners say in the real life situations. This might be due to the fact that the modifications and situational variables have been controlled in order to elicit targeted speech acts. Consequently, the data elicited from the WDCT cannot reflect important cultural values that may be particular to certain speech community.

Lastly, the learners are not able to extend the negotiation of meaning of the speech acts in the WDCT. This indicates that there is no access to complete combination of interpersornal and contextual details in the WDCT (Varghese, \& Billmyer, 1996). In other words, the WDCT may not illuminate the learners' internal negotiation when they are interacting each other in the real situations. For instance, when a speaker gives advice to someone who is not familiar with, the WDCT does not give a clear picture how the speakers negotiate the message delivered and encounter the problems if the advice is not accepted. This makes the use of WDCT limited in terms of the negotiation of meaning in the real interaction.

\section{PEDAGOGICAL IMPLICATIONS}

Having reviewed the benefits and the pitfalls of using the WDCT as an assessment tool of learner's pragmatic competence, it is obviously seen that this is not an easy task to construct a testing instrument of pragmatic competence. The teacher has to design this testing instrument as accurate as possible so that this can adequately examine learners' pragmatic competence holistically. At the end, the learners can be stimulated to use their real language when they are assigned to complete the WDCT. More specifically, the learners are able not only to show their grammatical competence, but also to use the language in appropriate contexts. Thus, the teacher should figure out some ways to design the WDCT in order to use it effectively in the assessment process.

With regard to develop and design a test of pragmatic competence, the teacher should pay attention to five stages (Jianda, 2007; Birjandi \& Rezaei, 2010). Firstly, exemplar generation should be determined before the test is constructed. In the exemplar generation stage, the teacher asks the learners to identify and classify situations, which are applicable for them in certain speech acts. This is one of the ways to ascertain the authenticity of the test, which is very important aspect in order to have a communicative language testing. In the same vein, Bachman and Palmer (1996) confirm that authenticity is one of the elements which ensures the 
quality of language test and has a great impact on learners' performance. The second stage is situation likelihood investigation. The teacher in this stage examines how likely it is that the situations prompted in learners' daily life interactions. This is also related to the authenticity element in determining the quality of language testing. Next, the teacher conducts metapragmatic assessments. This assessment is done in order to collect learners' perceptions of the contextual variables included in each constellation. The contextual variables, such as, social distance, relative power, degree of impositions, may be different between one to another cultural context which depend on learners' cultural-specific and sociopragmatic element. The fourth stage is to pilot the situations of the test. This stage should be conducted in order to validate the scenarios used to elicit learners' speech act production and to obtain preliminary data to construct each constellation of the WDCT. Finally, the teacher develops the constellation of the WDCT. In this stage, the teacher analyses the data collected from the situational pilot test. After analysing the result and developing the test, it is suggested that the developed test is piloted again to another group of learners so that the test will have a good quality in terms of validity, reliability, practicality, and authenticity.

\section{CONCLUSION}

In conclusion, while the WDCT has some limitations, this tool can be used effectively to assess learners' pragmatic competence. In other words, although the WDCT cannot facilitate to capture the complete interaction of natural speech, the WDCT is able to represent learners' pragmatic competence with regard to the communicative aspect of language testing. Moreover, the WDCT does not only reflect the learners' linguistic competence, but also show how the learners use the language in the communicative context based on sociocultural variables. Regarding the development of the WDCT as one of the pragmatic tests, there are five stages that should be considered in constructing the test, namely exemplar generation, situation likelihood investigation, metapragmatic assessment, situational pilot test, and test development stages. These stages should be conducted in constructing and developing a good quality of the assessment tool of pragmatic competence. Therefore, the teacher can use the WDCT effectively to assess learners' pragmatic competence and minimize the limitations of the test. 


\section{References}

Ahn, R. C. (2005). Five measures of interlanguage pragmatics in KFL (Korean as foreign language) learners. (Doctoral dissertation, University of Hawaii at Manoa, 2005). Retrieved from sunzi.lib.hku.hk/ER/detail/hkul/3842082.

Bachman, L.F. (1990). Fundamental considerations in language testing. Oxford: Oxford Univeristy Press.

Birjandi, P. \& Rezaei, S. (2010). Developing a multiple-choice discourse completion test of interlanguage pragmatics for Iranian EFL learners. Proceedings of the First Conference on ELT in the Islamic World, 6, 43-58. Retrieved from http://atu-ir.academia.edu/SaeedRezaei/Papers.

Brock, M.N. \& Nagasaka, Y. (2005). Teaching pragmatic in the EFL classroom? Sure you can! TESL Reporter, 38(1), 17-26.

Decapua, A. \& Dunham, J.F. (2007). The pragmatics of advice giving: Crosscultural perspective. Intercultural Pragmatics, 4(3), 319-342. doi: 10.1515/IP.2007.016.

Hudson, T., Detmer, E., \& Brown, J. D. (1995). Developing prototypic measures of cross-cultural pragmatics. Honolulu: University of Hawaii, Second Language Teaching and Curriculum Center.

Jernigan, J.E. (2007). Instruction and developing second language pragmatic competence: An investigation into the efficacy of output. (Doctoral dissertation, Florida State University, 2007). Retrieved from http://diginole.lib.fsu.edu/etd/3523.

Jianda, L. (2006). Assessing EFL learners' interlanguage pragmatic knowledge: Implications for testers and teachers. Reflection on English Language Teaching, 5(1), 1-22.

. (2007). Developing a pragmatic test for Chinese EFL learners. Language Testing, 24, 391-415.

Jie, C. (2005). A comparative study of Chinese EFL learners' performances in different pragmatic tests. (Master thesis, Nanjing University, 2005). Retrieved from

www.cxrlinguistics.com/UploadFile/201191983513522.pdf. 
Kasper, G. (2000). Data collection in pragmatics research. In H. Spencery-Oatey (Ed.), Culturally speaking: Managing rapport through talk across cultures 